\begin{tabular}{|c|c|}
\hline Title & Photoswitchable CENP-E Inhibitor Enabling the Dynamic Control of Chromosome Movement and Mitotic Progression \\
\hline Author(s) & Mafy, Noushaba Nusrat; Matsuo, Kazuya; Hiruma, Shota; U ehara, Ryota; T amaoki, Nobuyuki \\
\hline Citation & $\begin{array}{l}\text { Journal of the A merican Chemical Society, 142(4A ), 1763-1767 } \\
\text { https://doi.org/10.1021/ } a \text { acs.9b12782 }\end{array}$ \\
\hline Issue Date & $2020-01-29$ \\
\hline Doc URL & http:/hdl.handle.net/2115/80343 \\
\hline Rights & $\begin{array}{l}\text { This document is the A ccepted Manuscript version of a Published Work that appeared in final form in Journal of the } \\
\text { A merican Chemical Society, copyright } \odot \text { A merican Chemical Society after peer review and technical editing by the } \\
\text { publisher. To access the final edited and published work see https:/pubs.acs.org/doi/10.1021/Jacs.9b12782. }\end{array}$ \\
\hline Type & article (author version) \\
\hline File Information & revised+MS-final.pdf \\
\hline
\end{tabular}

Instructions for use 


\title{
Photoswitchable CENP-E inhibitor enabling the dynamic control of chromosome movement and mitotic progression
}

\author{
Noushaba Nusrat Mafy ${ }^{\dagger}$, Kazuya Matsuo ${ }^{\dagger}$, Shota Hiruma ${ }^{\ddagger}$, Ryota Uehara ${ }^{\ddagger}, \#$, , Nobuyuki Tamaoki ${ }^{\dagger, *}$ \\ ${ }^{\dagger}$ Research Institute for Electronic Science, Hokkaido University, Kita 20, Nishi 10, Kita-ku, Sapporo, 001-0020, Japan \\ ${ }^{\ddagger}$ Graduate School of Life Science, Hokkaido University, Kita 21, Nishi 11, Kita-ku, Sapporo, 001-0021, Japan \\ ${ }^{\#}$ Faculty of Advanced Life Science, Hokkaido University, Kita 21, Nishi 11, Kita-ku, Sapporo, 001-0021, Japan
}

Supporting Information Placeholder

\begin{abstract}
Interfering with mitosis is a potential cancer therapy strategy. However, the lack of controllability of anti-mitotic drugs in cell growth suppression causes severe side effects and limits their clinical utility. Herein, we developed an azobenzene-based photoswitchable inhibitor of CENP-E, a mitotic kinesin required for chromosome transportation. The new inhibitor enabled reversible photoswitching of CENP-E activity with 10fold change in $\mathrm{IC}_{50}$ between cis and trans photoisomerization states both in vitro and in living cells. It also enabled repeatable photoswitching of CENP-E-dependent chromosome congression and hence mitotic progression with UV/Vis light illumination cycles. Using this technique, we could specify the exact process of mitotic progression in which CENP-E plays an indispensable role. Our data demonstrate the power of photochemical approach for highly controllable mitotic interference as well as for discovery of precise molecular functions in dynamic cellular processes.
\end{abstract}

During mitosis in eukaryotes, replicated chromosomes are equally segregated into two daughter cells to precisely transmit genetic information. ${ }^{1}$ This process is mediated by a microtubule-based bipolar structure, the mitotic spindle. The spindle captures all chromosome pairs at their kinetochores, transports them to cell equatorial plane at metaphase by motor proteins, and then separates each pair into opposite cellular poles during anaphase. Accurate mitotic progression is secured by spindle assembly checkpoint (SAC) that is activated in the presence of uncaptured chromosomes and stops mitotic progression until all chromosomes are captured and aligned by the spindle. ${ }^{2}$ Spindle malfunctioning causes prolonged mitotic arrest, eventually leading to cell death. Therefore, development of inhibitors that block spindle function has been a promising strategy for cancer therapy, and enormous efforts have been made to discover spindle-associated genes and determine their functions..$^{3-5}$ However, a drawback of anti-mitotic cancer therapy is its potential side effects on normal proliferative cells, which limits their clinical application. Photopharmacological tools such as photostatins $^{6}$ to reversibly control microtubule dynamics with light illumination may overcome this limitation, and development of photoswitchable tools for a wide variety of targets would facilitate tissue-selective mitotic inhibition.
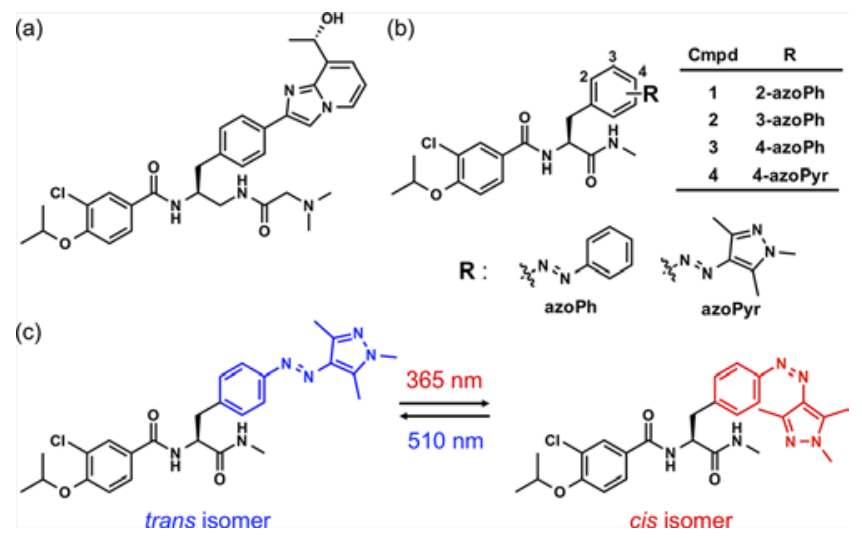

Figure 1. (a) Authentic CENP-E inhibitor, GSK923295. (b) Chemical structures of photo-switchable CENP-E inhibitors. (c) Reversible cis-trans photoisomerization of $\mathbf{4}$.

Different types of microtubule-associated motor proteins make specialized contributions to force generation in dynamic reorganization of spindle microtubules and chromosome segregation. ${ }^{7}$ Among them, centromere-associated protein E (CENP-E; kinesin-7) binds to the kinetochores and transports chromosomes along spindle microtubules from the spindle poles toward the equatorial plate to complete chromosome congression. ${ }^{8}$ GSK923295 (Figure 1a) is a selective CENP-E inhibitor under clinical trials, which locks CENP-E in a "rigor" microtubule-bound state by blocking inorganic phosphate release in its ATPase cycle. ${ }^{9-11}$ 
(a)

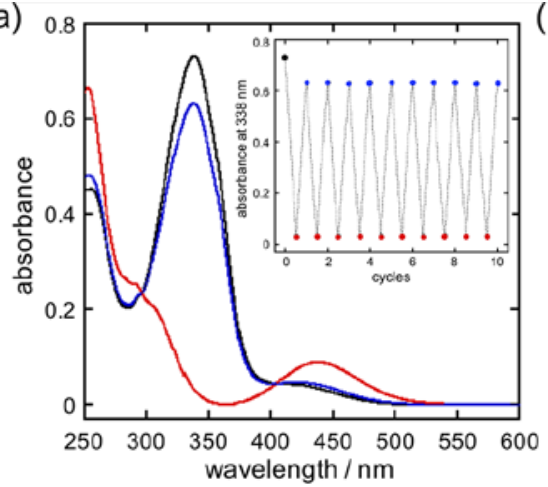

(b)

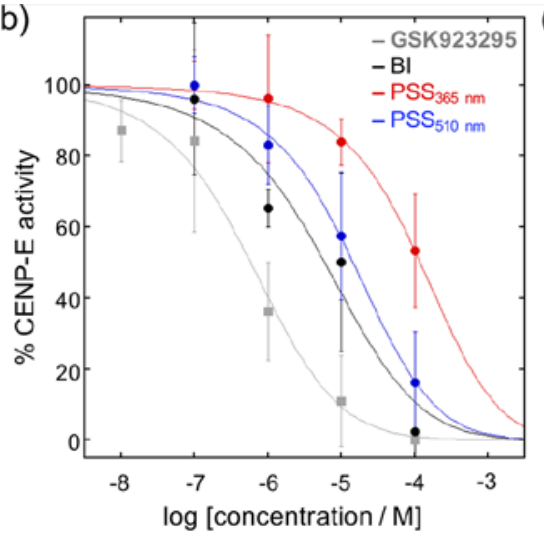

(d)

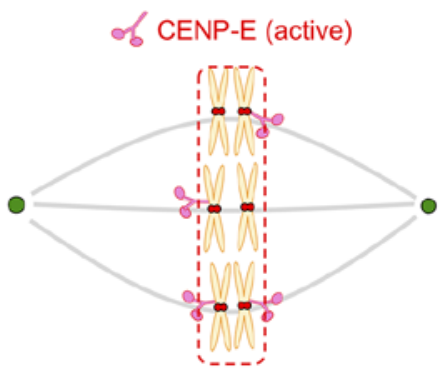

"aligned" chromosomes at the metaphase plate

of CENP-E (inhibited)

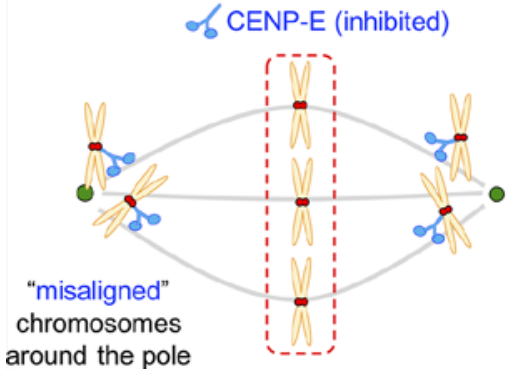

(e)

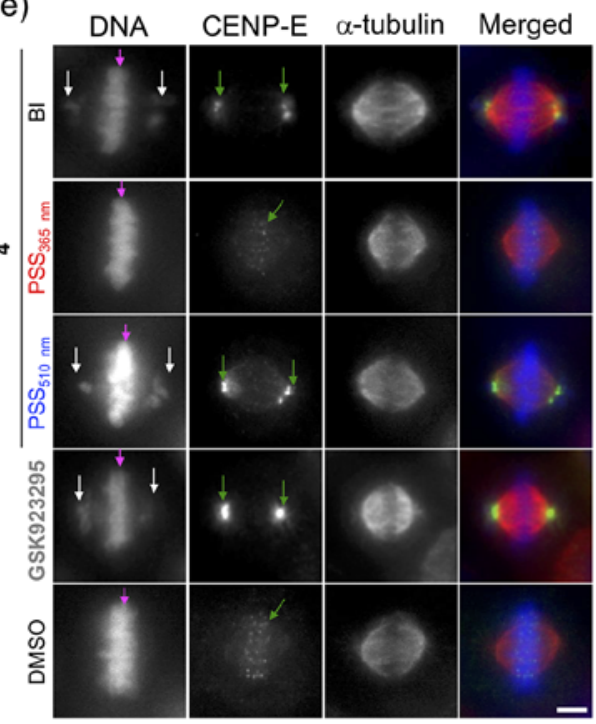

(c)

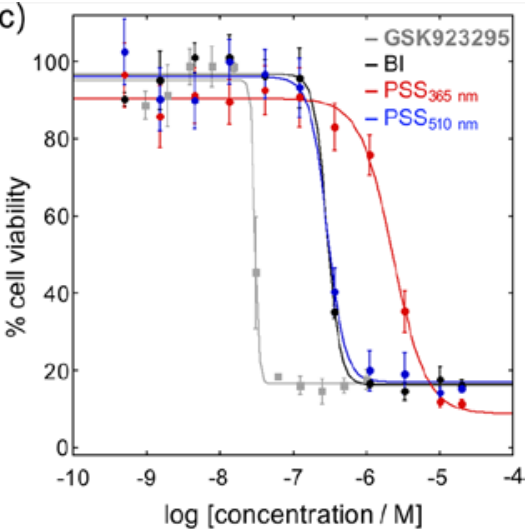

(f)

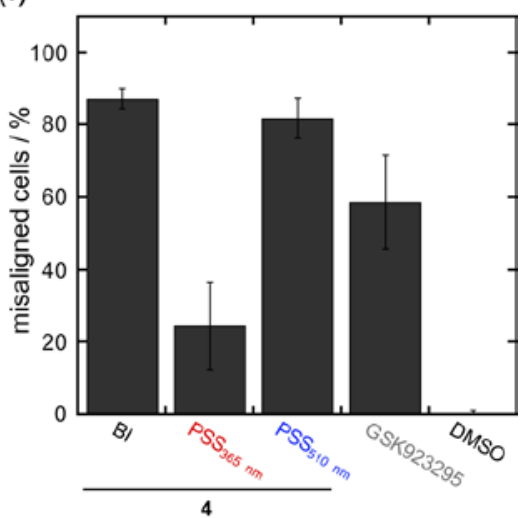

Figure 2. (a) Absorption spectra of $4(33 \mu \mathrm{M})$ in BRB-80 buffer (pH 6.9): acetonitrile (1:1) solution at room temperature before light illumination (BI, black), at PSS $_{365 \mathrm{~nm}}$ (red), or at PSS $510 \mathrm{~nm}$ (blue). Inset: Absorbance changes at 338 nm under alternating 365/510 nm illumination. (b, c) CENP-E ATPase assay (b) or cell proliferation assay (c) with GSK923295 (gray)

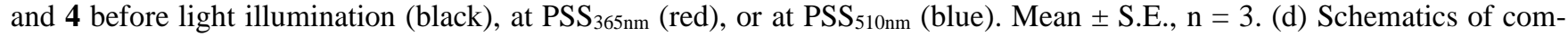
pletely-aligned chromosomes with active CENP-E and misaligned polar chromosomes with inhibited CENP-E. (e) Immunofluorescence of CENP-E and $\alpha$-tubulin in HeLa cells treated with DMSO, GSK923295 $(1.0 \mu \mathrm{M})$ or $4(1.0 \mu \mathrm{M})$ in the presence of MG-132 $(20 \mu \mathrm{M})$ for $2 \mathrm{~h}$. Scale bar, $5 \mu \mathrm{m}$. White, magenta, or green arrows indicate misaligned chromosomes, aligned chromosomes, or CENP-E accumulation, respectively. (f) Frequency of misaligned chromosomes in DMSO-, GSK923295$(2.0 \mu \mathrm{M})$ or $4-(1.0 \mu \mathrm{M})$ treated cells (Mean \pm S.E., $n=3,>150$ cells in total). Light intensities in all experiments were described in Supporting Information.

Previous studies have found that GSK923295 inhibits chromosome alignment and mitotic progression in cancer cells and also suppresses tumor growth in xenograft models. ${ }^{9-10,12-13}$ However, despite of its potential as a cancer therapeutic target, there has been no report on development of a photoswitchable CENP-E inhibitor to date.

Herein, we describe a photochemical approach for control of CENP-E functions using cis-trans photoisomerization of azobenzene derivatives that we previously used for photoregulation of motor proteins. ${ }^{14-15}$ Our photoswitchable CENP-E inhibitor enabled dynamic modulation of CENP-E-dependent chromosome movement and mitotic progression in high temporal resolution, providing a potential optotherapeutic method and a new tool for studying precise role of CENP-E in mitosis.

To design the photoswitchable CENP-E inhibitors, we employed the well-established molecular scaffold of azobenzene derivatives as a reversible photoswitch for photopharmacology. ${ }^{16-19}$ The core imidazopyridine ring in GSK923295 ${ }^{10}$ was replaced with azobenzene derivatives (Figure 1b). We synthesized 1-3 with a phenylazo group (azoPh) at 2-, 3-, 4-position, respectively, and $\mathbf{4}$ with a pyrazolylazo group (azoPyr) at 4-position (Figure 1b; Supporting information Figure S12-S59), which was previously reported to exhibit high photoswitchability ${ }^{20}$. 
Photoswitchability of 1-4 was studied using absorption spectroscopy with ultraviolet (UV) and visible (Vis) light illumination in aqueous solution (Figure 2a and S1). Before light illumination, 1-4 in pure trans isomer (Figure S2) exhibited two absorption bands corresponding to $\pi-\pi^{*}$ (around $330 \mathrm{~nm}$ ) and $\mathrm{n}-\pi^{*}$ (around $440 \mathrm{~nm}$ ) electronic transitions. These intensities were dramatically altered upon $365 \mathrm{~nm}$ or $436 \mathrm{~nm}$ light illumination to reach photostationary state (PSS) containing $>70 \%$ cis or trans isomer, respectively, for 1-3 (determined by HPLC in Figure S2, Table S1). Presumably due to the well-separated electronic transitions in arylazopyrazole ${ }^{20}, 4$ showed higher photo-switchability (93\% of cis isomer at PSS $_{365 n m}$ and $86 \%$ of trans isomer at PSS $_{510 \mathrm{~nm}}$ ) than 1-3. All compounds underwent the reversible cis-trans photoisomerization for many cycles without any fatigue. Thermal relaxation lifetimes for cis isomers in $\mathbf{1 - 4}$ were $>24 \mathrm{~h}$ at 37 ${ }^{\circ} \mathrm{C}$ (Figure S3, Table S1).

Next, we investigated inhibitory effects on steady-state ATPase activity of purified CENP-E using an NADHcoupled method ${ }^{21}$. Due to the poor water solubility of 13 , their inhibitory activities were tested at the maximum concentration of $5 \mu \mathrm{M}$ in BRB80 buffer containing $10 \%$ DMSO (Figure S4). Only 3 bearing 4-azoPh in pure trans form inhibited CENP-E before light illumination (46\% inhibition at $5 \mu \mathrm{M}$ ), whereas no inhibitory effect was shown at PSS $365 \mathrm{~nm}$. Compared to 1-3, 4 showed much better water solubility ( $>100 \mu \mathrm{M}$ in BRB-80 buffer containing $0.1 \%$ DMSO) and inhibited ATPase activity in nonlight illuminated condition ( $\mathrm{IC}_{50} 5.9 \mu \mathrm{M}$ ), which was ca. 10 -fold less potent than GSK923295 (IC $50.58 \mu \mathrm{M}$ ). The efficacy of $\mathbf{4}$ dramatically decreased at PSS $_{365 \mathrm{~nm}}\left(\mathrm{IC}_{50} 120\right.$ $\mu \mathrm{M})$ but remained equivalent to the non-light illuminate state at PSS $_{510 \mathrm{~nm}}\left(\mathrm{IC}_{50} 14 \mu \mathrm{M}\right)$, demonstrating its sharp photoswitchability of the inhibitory property (Figure $2 \mathrm{~b}$ ). These trends are probably because only the extended structures included in trans-3 and $\mathbf{4}$, not in these cis isomers are acceptable to the sterically restricted binding site of CENP-E. In microtubule co-sedimentation assay, $\mathbf{4}$ induced stable binding between polymerized microtubules and CENP-E with ADP in non-light illuminated condition or at PSS $_{510 \mathrm{~nm}}$, but to lesser extent at $\mathrm{PSS}_{365}$ (Figure S5). Therefore, similarly to GSK923295, 4 also locked CENP-E in a rigor microtubule-bound state, but in a photo-switchable manner.

To determine whether $\mathbf{4}$ effects the intracellular function of CENP-E in a photo-switchable manner, we compared proliferation of HeLa cells treated with GSK923295 or $\mathbf{4}$ for $48 \mathrm{~h}$ with or without $12 \mathrm{~h}$-interval light illumination in colorimetric cell proliferation assay (Figure 2c and S6). Consistent with previous studies ${ }^{10}$, GSK923295 exhibited strong cell growth inhibition with IC $_{50} 30 \mathrm{nM}$. Cell viability was not affected by light illumination either in the presence or absence of GSK923295, ruling out possible side effects of light illumination on essential cellular processes (Figure S6). On the other hand, 4 had substantially higher efficacy at non-illuminated state $\left(\mathrm{IC}_{50} 0.29 \mu \mathrm{M}\right)$ or $\mathrm{PSS}_{510 \mathrm{~nm}}\left(\mathrm{IC}_{50} 0.29 \mu \mathrm{M}\right)$ than at PSS $_{365 n m}\left(\mathrm{IC}_{50} 2.4 \mu \mathrm{M}\right)$. Therefore, although its efficacy on cell proliferation was ca. 10-fold less than that of GSK923295, 4 showed evident photoswitchability of cell proliferation inhibition.

To gain further insight into inhibitory mechanism of $\mathbf{4}$, we investigated the effect of GSK923295 or 4 in spatial distribution of the chromosomes and endogenous CENP$\mathrm{E}$ in HeLa cells by immunofluorescence using antiCENP-E antibody (Figure 2d and e). To facilitate the analysis of chromosome dynamics in pre-anaphase, during which CENP-E-dependent chromosome congression takes place, anaphase onset was blocked by a proteasome inhibitor MG-132 in all conditions. ${ }^{22}$ In control, all mitotic cells possessed completely aligned chromosomes at the metaphase plate with evident accumulation of CENP$\mathrm{E}$ at their kinetochores (Figure 2d-f and S7). As previously reported ${ }^{10,23}$, GSK923295 induced frequent misalignment of chromosomes at spindle poles. In this condition, CENP-E was delocalized from the kinetochores, and instead ectopically accumulated to the spindle poles due to microtubule treadmilling that drives poleward movement of the rigor-bound CENP-E (Figure 2e). ${ }^{10,22}$ Similar chromosome misalignment was induced by 4 in $>80 \%$ cells at non-illuminated state or PSS ${ }_{510 \mathrm{~nm}}$, while it was in less than $30 \%$ cells at PSS $_{365 \mathrm{~nm}}$. The 4 -induced chromosome misalignment at non-illuminated state or PSS $_{510 \mathrm{~nm}}$ was also accompanied by evident CENP-E delocalization. This indicates that $\mathbf{4}$ blocks CENP-E at rigor state in living cells and perturbs chromosome congression in a photo-switchable manner.

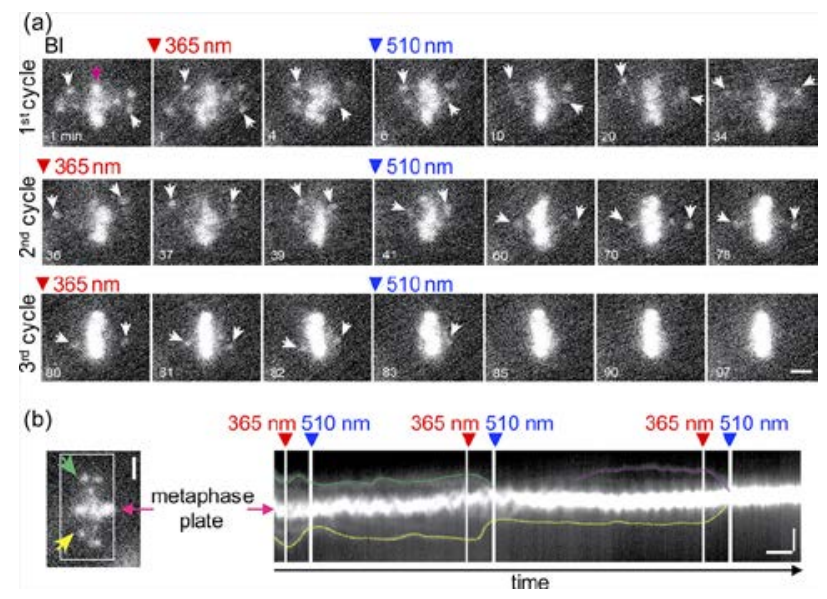

Figure 3. (a) Live imaging of mitotic chromosomes in a 4treated LLC-PK1 cell under alternating $365 \mathrm{~nm}$ (red) and $510 \mathrm{~nm}$ (blue) light illumination. White arrows: misaligned chromosomes. (b) A kymograph of mitotic chromosome movement along cell division axis. The misaligned chromosomes are highlighted and tracked by lines with different colors. Vertical bars, $5 \mu \mathrm{m}$. Horizontal bar, 5 min. 
(a)

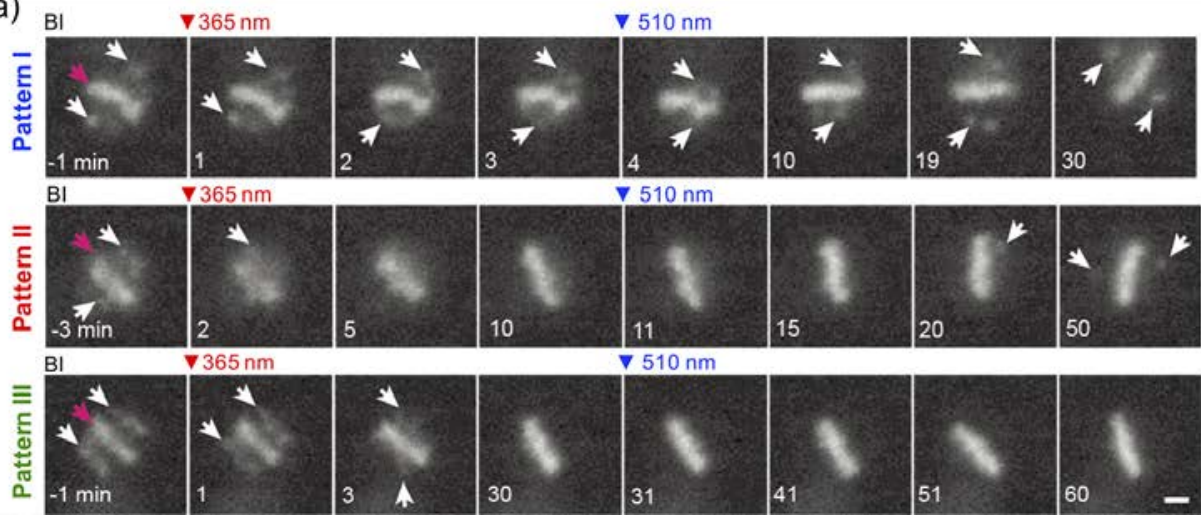

(b)

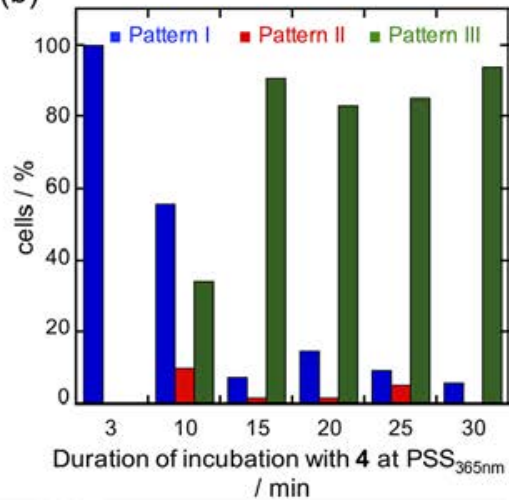

Figure 4. (a) Live imaging of 4-treated HeLa cells under alternating 365/510 nm light illumination. White or magenta arrows indicate misaligned or aligned chromosomes, respectively. The timing of $365 \mathrm{~nm}$ light illumination was set as $0 \mathrm{~min}$. Chromosome dynamics were categorized into three patterns as described in the main text. Scale bar, $5 \mu \mathrm{m}$. (b) Frequency of different chromosome dynamics patterns in (a). At least 38 mitotic cells containing misaligned chromosomes before light illumination from two independent experiments were analyzed for each condition.

We further investigated 4-mediated photo-control of chromosome congression by live imaging with alternating $365 \mathrm{~nm}$ and $510 \mathrm{~nm}$ light illumination. To facilitate chromosome tracking at high magnification, we used LLC-PK1 cells that has a flat cell morphology in mitotic phase. Chromosomes were stained with far-red fluorescent dye (SiR-DNA) not to affect photoisomerization of 4 by the excitation light (Figure S8). Consistent with the fixed cell analysis, pretreatment with $\mathbf{4}$ induced misaligned polar chromosomes before light illumination. However, after $365 \mathrm{~nm}$ light illumination, the misaligned polar chromosomes gradually moved toward the equatorial plane. By the subsequent $510 \mathrm{~nm}$ light illumination, the equator-ward movement of the misaligned chromosomes immediately ceased and substantial portion of them started to move toward the spindle poles (Figure 3a, movie S1). This suggests immediate inhibition of CENP$\mathrm{E}$ by $\mathbf{4}$ upon photoisomerization to $\mathrm{PSS}_{510 \mathrm{~nm}}$. Direction of the chromosome movement changed repeatedly in the subsequent light illumination cycle, demonstrating a repeatable photoswitching of chromosome congression by 4 (Figure $3 \mathrm{~b}$ and S9).

During this experiment, we noticed that chromosomes that had once completely aligned at the equatorial plane at PSS $_{365 n m}$ did not immediately come out of the metaphase plate at the subsequent PSS $_{510 \mathrm{~nm}}$. This indicates that, while CENP-E is continuously required for congression of chromosomes, it becomes dispensable once these chromosomes are aligned. It has been controversial whether CENP-E plays active roles in the maintenance of chromosome alignment. ${ }^{24}$ Since $\mathbf{4}$ is an ideal chemical tool to investigate contribution of CENP-E to different stages of mitosis, we further addressed this issue using a systematic UV/Vis illumination cycle in HeLa cells (Figure 4). Cells were co-treated with MG-132 and $\mathbf{4}$ at non-illuminated state to induce chromosome misalignment, incubated for different duration (3-30 min) at PSS $_{365 \mathrm{~nm}}$ to induce chromosome congression to various extent, and then further incubated at PSS ${ }_{510 \mathrm{~nm}}$ for $30 \mathrm{~min}$. In case cells were incubated only for $3 \mathrm{~min}$ at $\mathrm{PSS}_{365 \mathrm{~nm}}$, misaligned chromosomes still remained in all cells at the end of PSS $_{365 \mathrm{~nm}}$, and these chromosomes immediately stopped congression or started to move poleward at the subsequent PSS $_{510 \mathrm{~nm}}$ (pattern I in Figure 4a). As the duration of PSS $_{365 \mathrm{~nm}}$ increased, larger population of cells completed

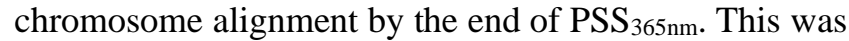
further confirmed by clearance of a SAC component Mad2 from the kinetochores, which occurs only after establishment of the end-on attachment of spindle microtubules on the kinetochore (Figure S10). ${ }^{25-26}$ Importantly, among the cells that completed chromosome alignment during PSS $_{365 n m}$, very small population showed chromosome re-misalignment within $30 \mathrm{~min}$ at the subsequent PSS $_{510 \mathrm{~nm}}$ (pattern II), whereas vast majority of them maintained complete chromosome alignment (pattern III). Quantification clearly demonstrates time-dependent transition from pattern I to III in the mode of chromosome dynamics in light illumination cycle (Figure 4b). Further extension of PSS $_{510 \mathrm{~nm}}$ resulted in a gradual increase in chromosome re-misalignment, but more than $50 \%$ of cells kept complete alignment even after 3-h incubation at PSS $_{510 \mathrm{~nm}}$ (Figure S11). These data demonstrate that CENP-E activity is not required for the maintenance of chromosome alignment within the physiologically-relevant time frame of mitotic progression (i.e. $30 \mathrm{~min}$ ), whereas its inhibition impairs the maintenance of extremely prolonged metaphase state.

In summary, we successfully developed the photoswitchable CENP-E inhibitor 4 that enabled reversible switching of CENP-E activity both in vitro and in the intracellular environment. Using this technique, we could modulate CENP-E-dependent chromosome movement and the progression of mitosis in a reversible manner. The fast photoswitching of $\mathbf{4}$ also enabled us to specify the exact mitotic stage in which CENP-E plays an indispensable role. Our data demonstrate the power of reversible photo- 
regulatory tool in elucidating molecular functions in dynamic cellular processes. Considering potential high spatial resolution of photochemical technics, it would be an intriguing future study to apply our inhibitor for specific growth suppression of cancer cells within living organisms, which may open up an avenue of a novel scheme for cancer therapy.

\section{ASSOCIATED CONTENT}

\section{Supporting Information.}

The Supporting Information is available free of charge on the ACS Publications website.

Experimental procedures and additional data (PDF)

Movie S1: Dynamic photoregulation of mitotic chromosomes in a living cell (AVI)

\section{AUTHOR INFORMATION}

\section{Corresponding Author}

E-mail for N.T.: tamaoki@es.hokudai.ac.jp or for R.U.: ruehara@sci.hokudai.ac.jp

Notes

The authors declare no competing financial interest.

\section{ACKNOWLEDGMENT}

We thank Dr. Daniel W. Gerlich (IMBA, Austria) for the Mad2-GFP/H2B-mCherry HeLa cell line. We also thank the Instrumental Analysis Division of the Global Facility Center (Creative Research Institution, Hokkaido University) for HR-MS measurements with Thermo Scientific Exactive, and for providing insight and expertise. This work was performed under the International Cooperative Research Program of "Dynamic Alliance for Open Innovation Bridging Human, Environment and Materials" in "Network Joint Research Center for Materials and Devices". This work was supported by JSPS KAKENHI for Early-Career Scientists (Grant \# 19K15709), Takeda Science Foundation, The Tokyo Biochemical Research Foundation, Konica Minolta Science and Technology Foundation, Noguchi Foundation, Japan Foundation for Applied Enzymology, Foundation for Interaction in Science \& Technology, and Akiyama Life Science Foundation to K.M, Grants-in-Aid for Scientific Research B (Grant \# 19H03219), on Innovative Areas "Singularity Biology (No.8007)” (19H05413) and Fostering Joint International Research B (19KK0181) of MEXT, the Orange Foundation, the Smoking Research Foundation, and the Kato Memorial Bioscience Foundation to R.U., and Grantsin-Aid for Scientific Research B (Grant \# 18H02042) to N.T.

\section{REFERENCES}

(1) Batty, P.; Gerlich, D. W. Mitotic Chromosome Mechanics: How Cells Segregate Their Genome. Trends Cell Biol. 2019, 29, 717-726.

(2) Long, A. F.; Kuhn, J.; Dumont, S. The mammalian kinetochoremicrotubule interface: robust mechanics and computation with many microtubules. Curr. Opin. Cell Biol. 2019, 60, 60-67.

(3) Tischer, J.; Gergely, F. Anti-mitotic therapies in cancer. J. Cell Biol. 2019, 218, 10-11.

(4) Prosser, S. L.; Pelletier, L. Mitotic spindle assembly in animal cells: a fine balancing act. Nat. Rev. Mol. Cell Biol. 2017, 18, 187-201.
(5) Mitchison, T. J.; Pineda, J.; Shi, J.; Florian, S. Is inflammatory micronucleation the key to a successful anti-mitotic cancer drug? Open Biol. 2017, 7, 170182.

(6) Borowiak, M.; Nahaboo, W.; Reynders, M.; Nekolla, K.; Jalinot, P.; Hasserodt, J.; Rehberg, M.; Delattre, M.; Zahler, S.; Vollmar, A.; Trauner, D.; Thorn-Seshold, O. Photoswitchable Inhibitors of Microtubule Dynamics Optically Control Mitosis and Cell Death. Cell 2015, 162, 403-411.

(7) Yount, A. L.; Zong, H.; Walczak, C. E. Regulatory Mechanisms that Control Mitotic Kinesins. Exp. Cell Res. 2015, 334, 70-77.

(8) Wood, K. W.; Sakowicz, R.; Goldstein, L. S. B.; Cleveland, D. W. CENP-E Is a Plus End-Directed Kinetochore Motor Required for Metaphase Chromosome Alignment. Cell 1997, 91, 357-366.

(9) Qian, X.; McDonald, A.; Zhou, H.-J.; Adams, N. D.; Parrish, C. A.; Duffy, K. J.; Fitch, D. M.; Tedesco, R.; Ashcraft, L. W.; Yao, B.; Jiang, H.; Huang, J. K.; Marin, M. V.; Aroyan, C. E.; Wang, J.; Ahmed, S.; Burgess, J. L.; Chaudhari, A. M.; Donatelli, C. A.; Darcy, M. G.; Ridgers, L. H.; Newlander, K. A.; Schmidt, S. J.; Chai, D.; Colón, M.; Zimmerman, M. N.; Lad, L.; Sakowicz, R.; Schauer, S.; Belmont, L.; Baliga, R.; Pierce, D. W.; Finer, J. T.; Wang, Z.; Morgan, B. P.; Morgans Jr., D. J.; Auger, K. R.; Sung, C.-M.; Carson, J. D.; Luo, L.; Hugger, E. D.; Copeland, R. A.; Sutton, D.; Elliott, J. D.; Jackson, J. R.; Wood, K. W.; Dhanak, D.; Bergnes, G.; Knight, S. D. Discovery of the First Potent and Selective Inhibitor of Centromere-Associated Protein E: GSK923295. ACS Med. Chem. Lett. 2010,1, 30-34.

(10) Wood, K. W.; Lad, L. Luo, L.; Qian, X.; Knight, S. D.; Nevins, N.; Brejc, K.; Sutton, D.; Gilmartin, A. G.; Chua, P. R.; Desai, R.; Schauer, S. P.; McNulty, D. E.; Annan, R. S.; Belmont, L. D.; Garcia, C.; Lee, Y.; Diamond, M. A.; Faucette, L. F.; Giardiniere, M.; Zhang, S. Y.; Sun, C.-M.; Vidal, J. D.; Lichtsteiner, S.; Cornwell, W. D.; Greshock, J. D.; Wooster, R. F.; Finer, J. T.; Copeland, R. A.; Huang, P. S.; Morgans Jr., D. J.; Dhanak, D.; Bergnes, G.; Sakowicz, R.; Jackson, J. R. Antitumor activity of an allosteric inhibitor of centromereassociated protein-E. Proc. Natl. Acad. Sci. U.S.A. 2010, 107, 58395844.

(11) Chung, V.; Heath, E. I.; Schelman, W. R.; Johnson, B. M.; Kirby, L. C.; Lynch, K. M.; Botbyl, J. D.; Lampkin, T. A.; Holen, K. D. Firsttime-in-human study of GSK923295, a novel antimitotic inhibitor of centromere-associated protein E (CENP-E), in patients with refractory cancer. Cancer Chemother. Pharmacol. 2012, 69, 733-741.

(12) Balamuth, N. J; Wood, A.; Wang, Q.; Jagannathan, J.; Mayes, P.; Zhang, Z.; Chen, Z.; Rappaport, E.; Courtright, J.; Pawel, B.; Weber, B.; Wooster, R. Sekyere, E. O.; Marshall, G. M.; Maris, J. M. Serial transcriptome analysis and cross-species integration identifies centromere-associated protein E as a novel neuroblastoma target. Cancer Res. 2010, 70, 2749-2758.

(13) Lock R. B.; Carol, H.; Morton, C. L.; Keir, S. T.; Reynolds, C. P.; Kang, M. H.; Maris, J. M.; Wozniak, A. W.; Gorlick, R.; Kolb, E. A.; Houghton, P. J.; Smith, M. A.; Initial testing of the CENP-E inhibitor GSK923295A by the pediatric preclinical testing program. Pediatr. Blood Cancer 2012, 58, 916-923.

(14) Kumar, K. R. S.; Kamei, T.; Fukaminato, T.; Tamaoki, N. Complete ON/OFF Photoswitching of the Motility of a Nanobiomolecular Machine. ACS Nano, 2014, 8, 4157-4165.

(15) Menezes, H. M.; Islam, M. J.; Takahashi, M.; Tamaoki, N. Driving and photo-regulation of myosin-actin motors at molecular and macroscopic levels by photo-responsive high energy molecules. Org Biomol. Chem. 2017,15, 8894-8903.

(16) Velema, W. A.; Szymanski, W.; Feringa, B. L. Photopharmacology: Beyond Proof of Principle. J. Am. Chem. Soc. 2014,136, 21782191.

(17) Hüll, K.; Morstein, J.; Trauner, D. In Vivo Photopharmacology. Chem. Rev. 2018,118, 10710-10747.

(18) Cabré, G.; Garrido-Charles, A.; González-Lafont, A.; Moormann, W.; Langbehn, D.; Egea, D.; Lluch, J. M.; Herges, R.; Alibeś, R.;Busqué, F.; Gorostiza, P.; Hernando, J. Synthetic Photoswitchable Neurotransmitters Based on Bridged Azobenzenes, Org. Lett. 2019, 21, 3780 -3784 .

(19) Lentes, P.; Stadler, E.; Roehricht, F.; Brahms, A.; Groebner, J.; Sonnichsen, F. D.; Gescheidt, G.; Herges, R. Nitrogen Bridged 
Diazocines: Photochromes Switching within the Near-Infrared Region with High Quantum Yields in Organic Solvents and in Water. J. Am. Chem. Soc. 2019, 141, 13592-13600.

(20) Weston, C. E.; Richardson, R. D.; Haycock, P. R.; White, A. J. P.; Fuchter, M. J. Arylazopyrazoles: Azoheteroarene Photoswitches Offering Quantitative Isomerization and Long Thermal Half-Lives. J. Am. Chem. Soc. 2014, 136, 11878-11881.

(21) Kiianitsa, K.; Solinger, J. A.; Heyer, W.-D. NADH-coupled microplate photometric assay for kinetic studies of ATP-hydrolyzing enzymes with low and high specific activities. Anal. Biochem. 2003, 321, 266-271.

(22) Gudimchuk, N.; Vitre, B.; Kim, Y.; Kiyatkin, A.; Cleveland, D. W.; Ataullakhanov, F. I.; Grishchuk, E. L. Kinetochore kinesin CENP-
$\mathrm{E}$ is a processive bi-directional tracker of dynamic microtubule tips. Nat. Cell Biol. 2013,15, 1079-1088.

(23) Wood, K. W.; Sakowicz, R.; Goldstein, L. S.; Cleveland, D. W. CENP-E is a plus end-directed kinetochore motor required for metaphase chromosome alignment. Cell, 1997, 91, 357-366.

(24) Maiato, H.; Gomes, A. M.; Sousa, F.; Barisic, M. Mechanisms of Chromosome Congression during Mitosis. Biology, 2017, 6, E13.

(25) Dick, A. E.; Gerlich, D. W. Kinetic framework of spindle assembly checkpoint signalling. Nat. Cell Biol. 2013, 15,1370-1377.

(26) Kuhn, J.; Dumont, S. Spindle assembly checkpoint satisfaction occurs via end-on but not lateral attachments under tension. J. Cell. Biol. 2017, 216, 1533-1542. 

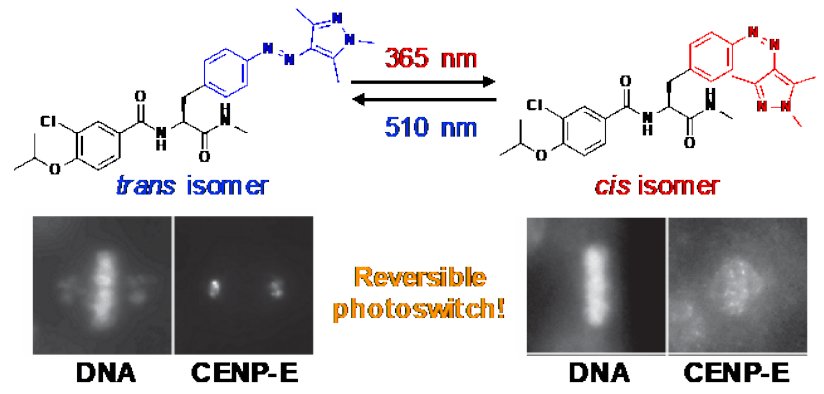

Revervilo photoswatch!

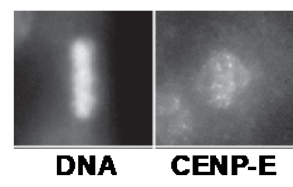

active CENP-E 